\title{
The Trees
}

of

\section{Commonwealth Avenue}

Boston 



\title{
The Trees \\ of
}

Commonwealth Avenue

Boston

\author{
By \\ Charles Sprague Sargent
}

Printed for the Author

1909 


$$
\frac{S B 48^{3}}{373^{3}}
$$

IIt czolange

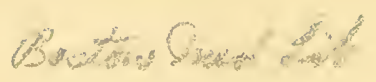

MAAR $20 \quad 1310$ 


\section{The Trees of Commonwealth Avenue}

To Messrs. Walter Hunnewell, F. G. Webster, and Walter C. BAYLIES:

Dear Sirs:- In compliance with your request I beg to submit the following statement in regard to the trees planted five years ago on Commonwealth Avenue between Dartmouth Street and Massachusetts Avenue.

The plan of using only two rows of trees on Commonwealth Avenue was first suggested, before trees had been planted on the Avenue west of Dartmouth Street, by Mr. F. L. Olmsted, the distinguished landscape-gardener, to whom the City of Boston is indebted for the comprehensiveness and beauty of its Park System, and by myself. In 1880, at the suggestion of the late Charles H. Dalton, at that time Chairman of the Board of Park Commissioners of Boston, Messrs. Olmsted and Sargent prepared a plan for planting Commonwealth Avenue. This plan proposed the removal of the four rows of trees then standing between Arlington and Dartmouth Streets and the planting in well prepared soil of two rows of trees from one end of the Avenue to the other. This plan was approved by Mr. Dalton and other residents on the Avenue but was not accepted by the City Government. The artistic and practical principles on which this plan was based are:

First: In order that a dignified vista of tree trunks may be secured each tree should stand opposite a tree in another row, and that the distance between the trees should be practically the same. These are fundamental rules now almost universally adopted in formal planting of this character.

Second: In order that uniformity in size, habit, color, and character of the bark and foliage, and in the time of foliation and defoliation of the trees may be obtained that only one variety should be used.

The Committee recommended setting the trees ten feet from the street line rather than in the middle of the planting spaces that they might have as much space as possible in which to extend their branches before the growth of these was arrested by the branches of the 


\section{[ 4] ]}

trees on the other side of the central walk, and not because it was believed that trees ten feet from the street would, as has been suggested, appear more dignified or beautiful, or better suited to their surroundings than trees standing twenty feet from the curb.

Commonwealth Avenue from Dartmouth Street to Massachusetts Avenue was planted in 1880 or 1881 by order of the Common Council with four rows of trees, the trees in the four rows standing opposite each other, so that the transverse distance between the trees of the inner rows was only about twenty feet, the trees in the rows being about forty feet apart. Between Dartmouth and Exeter Streets only American Elms were planted, and between Exeter Street and Massachusetts Avenue a large variety of European Elms was used.

There are several Elms popularly called English Elms in this country; among these are the Hedgerow or Field Elm, now common in southern England, the Scotch Elm, the Dutch Elm, and the Smooth-leaved Elm, and of each of these, with the exception of the first, there are many seminal varieties and probable hybrids. These species and varieties are very different in habit, rate of growth, hardiness, and time of foliation, and many of them are unsuited for street-planting in this part of the country owing to their irregular habit and want of hardiness; and of the so-called English Elms only the Field Elm in the peculiar form common in southern England has proved to be a good street tree in Massachusetts. It is this tree which was largely planted in eastern Massachusetts toward the end of the eighteenth century through the agency of Major Paddock, who established a nursery of this Elm in Milton; and it is this tree which has grown to a larger size in Boston than any other planted tree. This particular variety of Elm does not produce seeds, and as it can only be propagated by suckers or by grafting, it is necessary to use grafted trees as Messrs. Olmsted and Sargent recommended in their report of 1880 .

Before the trees between Dartmouth Street and Massachusetts Avenue had been planted for twenty years it became evident that this plantation could not be kept 
much longer in good condition. Between Dartmouth and Exeter Streets the American Elms of the inner rows, standing only twenty feet apart, were already dangerously crowded and were being destroyed by the more vigorous trees of the outer rows. Several of the foreign Elms west of Exeter Street had already died; others were unhealthy, and the unsatisfactory results which the mixing together in formal street-planting of different kinds of trees were becoming more and more evident every year.

Two courses seemed open to the Park Commission, - to let things remain as they were and allow the trees, badly selected, planted too close together in insufficient soil, with little chance of surviving for another twenty-five years, to die; or gradually to remove enough trees to make room for a new plantation made with one sort of tree and in a manner to insure for these trees the longest possible life.

If the Commission had adopted the first plan the appearance of the Avenue would have become less satisfactory as the trees gradually disappeared, and in a comparatively short time it would have been necessary to take down all the remaining trees, leaving the Avenue without any shade until new trees had grown. By adopting the second plan it was possible to replant the Avenue in a manner to secure healthy and longlived trees, and at the same time to preserve for several years enough of the older trees to give the appearance of a planted avenue until the younger trees had attained sufficient size to produce this effect. For this reason I recommended the Commission to change gradually from the four-row plan into a two-row plan.

From the plan prepared in 1880 by Messis. Olmsted and Sargent the plan recommended by me to the Commission seven years ago differs only in one particular. Instead of setting the trees ten feet from the street, as recommended in 1880 , the trees were planted in the middle of the loam space, because it was possible in this way to preserve for some years a larger number of the trees in the outer rows than it would have been possible to save had the new trees been planted nearer the roadways. 
There is no question that four rows of trees in Commonwealth Avenue would produce a better effect than the two rows, and that by the four-row plan the central walk and the two roadways would be more quickly shaded than by the trees in two rows. It is probable, moreover, that eight rows of trees would produce a better effect than four rows, but, unfortunately, certain conditions are fixed in the Avenue. The planting space in Commonwealth Avenue is one hundred feet wide. The growth of the English Field Elm in this neighborhood shows that in a space one hundred feet wide it is not possible to keep in good condition more than two rows of these trees for a period long enough to enable them to reach a height and size commensurate with the width and dignity of the Avenue, and that the trees even in two rows must become cramped and injured by the trees opposite them long before they can attain half their size.

Some idea of the probable growth of the young trees now planted on the Avenue can be formed by an examination of the row of Elm trees planted in 1876 by the Water Department of the City on Beacon Street near the Pumping Station of the Chestnut Hill Reservoir. These are grafted trees of the same variety and character as those planted in 1904 on Commonwealth Avenue. They have received no especial care. The ground on which they stand has not been cultivated for many years and has not been enriched, and the trees have not been pruned for a long time. These trees cannot be considered to have made an unusual or remarkable growth; and they have not reached more than a quarter of their full size. Many of these trees now have a spread of branches of forty-eight feet, and the smallest spread of branches of any of them does not appear to be less than forty-five feet. If the trees on Commonwealth Avenue grow no better than these Reservoir trees, they should, in 1934, extend their branches three feet over the central walk and over the roadways; and nine or ten years later the branches of the trees in the two rows should interlock over the central walk. At this time the trees would not be over 


\section{[ 7 ]}

one-third of their full size. Trees of this variety of Elm from fifty to sixty years old in the neighborhood of the City have a spread of branches varying from fifty to seventy feet.

The criticism that the two rows of trees west of Dartmouth Street will not harmonize with the fourrow plan east of Dartmouth Street does not need discussion, for the four rows can hardly be said to exist. Many of the trees planted in the four rows have died; others had become so unhealthy and deformed that their removal has been necessary. Of the one hundred and eighty-two trees originally planted in 1860-62 between Arlington and Dartmouth Streets only eightyfive are now standing. Ninety-seven of these trees have gone, besides a number of other trees planted from time to time on this part of the Avenue to replace dead trees. Of the number of such replanted trees there is unfortunately no record.

The condition and appearance of the trees in these plantations seems to offer sufficient arguments against an attempt to grow to maturity four rows of trees of the first size in a city planting space only one hundred feet wide and the use of more than one kind of tree in one city street, as is now proposed by the Park Commission. Their plan has in my opinion these objections:

First: The trees alternate in the rows instead of standing opposite.

Second: Each tree will stand only forty feet from its neighbor except at the end of the blocks where the space between two of the trees will be twenty feet. The plan, therefore, does not provide symmetry or sufficient space to permit the trees to grow for more than a few years.

Third: The trees in the outer rows, having the benefit of the light and space from the adjoining roadways, will grow more rapidly than the trees in the inner rows which will become crowded and deformed, and at the end of a few years the symmetry of the plantation will further be injured by the inevitably unequal size of the trees.

Fourth: The plan is impracticable and cannot be successfully executed for it calls for the planting together of larger and smaller trees, a system which is never successful, as has been shown in Commonwealth Avenue between Arlington and Dartmouth Streets 
where from time to time unsuccessful efforts have been made to plant small trees to fill the vacancies caused by the death of older trees. A still better example of the results which follow the mixing of large and small trees together in street-planting is found in Berlin where $\lambda_{\lambda}$ unter Den Linden young trees have been planted to take the place of older trees as these have given out. This plan has proved so unsatisfactory that an entirely new planting has now been made. The planting space is about the same width as in Commonwealth Avenue; and two rows of trees have now been used to replace the four rows of the original plantation.

Fifth: The plan provides for the use of several distinct varieties of trees different in habit, rate of growth, and hardiness. The use of more than one kind of tree in one city street has been given up in all modern systems of strect-planting, because different kinds of trees mixed together do not produce the formal and symmetrical effect which is needed in street-planting, and which can be produced only by the use of trees of one variety. The want of symmetry resulting from the use of several kinds of trees in one street is well illustrated in Commonwealth Avenue between Arlington and Dartmouth Streets, which may be compared with the Beacon and Charles Street malls of the Common where the good effect produced by using continuously one kind of tree is well shown.

Sixth: The adoption of the plan as it calls for the moving of all the trees planted in the spring of 1904 means unnecessary delay in supplying the Avenue with shade. These trees have grown rapidly and they already have long and large roots. Their removal from their present positions will retard their growth for several years. Some of them will probably die from the operation, and it may be expected that they will never become as good trees as they would have if they had not been moved.

Seventh: The adoption of this plan involves an unnecessary expenditure of money. In 1903-4, upon the recommendation of the Park Commission, the City spent ten thousand dollars in planting the two rows of trees on Commonwealth Avenue between Dartmouth Street and Massachusetts Avenue. The Commission now recommends a further expenditure of about twenty-four thousand dollars to undo its work of six years ago. This is something more than the waste of public money, for it destroys a good plan in the attempt to adopt another plan which it is impossible, under existing conditions, to carry out.

$$
\begin{aligned}
& \text { Yours very truly, } \\
& \text { C. S. SARgent. }
\end{aligned}
$$

Brookline, Mass., June 15, 1909. 

